\title{
Effects of a four week detraining period on physical, metabolic, and inflammatory profiles of elderly women who regularly participate in a program of strength training
}

\author{
Carolina P. Celestrin ${ }^{1}$, Guilherme Z. Rocha ${ }^{1,2}$, Angelica M. Stein ${ }^{1,3}$, Dioze Guadagnini' ${ }^{2}$, Rafael M. Tadelle ${ }^{1}$
} Mario J. A. Saad ${ }^{2}$ and Alexandre G. Oliveira ${ }^{1,2^{*}}$ (D)

\begin{abstract}
Background: Human aging has innumerable health implications, including loss of muscle mass and increased circulating inflammatory markers. Resistance exercise in the elderly can prevent muscle mass loss and improve the inflammatory profile. Conversely, detraining can reverse this picture. Thus, there is a strong need for studies with the elderly population to clarify the real impacts of a training interruption. Therefore, the objective of this study was to analyze the inflammatory profile of resistance trained elderly women after 4 weeks of detraining.

Methods: Seventeen elderly women with regular participation in an exercise program participated in the study. Body mass index (BMI), physical activity level assessments, total cholesterol and its fractions, triglycerides, glycemia and insulin blood levels, IL-1 $\beta, I L-4, \mathrm{IL}-6, \mathrm{IL}-10, \mathrm{LL}-13, \mathrm{TNF}-\mathrm{a}, \mathrm{IFN} \gamma$, and MCP-1 were assessed before and after the detraining protocol.

Results: The 4 week detraining period decreased physical fitness without altering body mass and BMI. The short detraining period was able to induce some metabolic disturbances in elderly women who regularly participate in a program of strength training, such as increasing HOMA-IR $(0.72 \pm 0.14$ to $0.81 \pm 0.23 ; p=0.029)$, and increasing total blood cholesterol $(178.21 \pm 23.64$ to $220.90 \pm 64.98 \mathrm{mg} / \mathrm{dL} ; p=0.008)$ and LDL fraction $(111.79 \pm 21.09$ to $155.33 \pm$ $60.95 \mathrm{mg} / \mathrm{dL} ; p=0.048)$. No alteration in levels of inflammatory cytokines was observed, however, this detraining period significantly reduced IL-13 (44.84 \pm 100.85 to $35.84 \pm 78.89 \mathrm{pg} / \mathrm{mL} ; p=0.031)$ a Th2 cytokine that induces M2 macrophage polarization.
\end{abstract}

\footnotetext{
* Correspondence: alexandre.gabarra@unesp.br

'Department of Physical Education, Bioscience Institute, Sao Paulo State University (UNESP), Rio Claro, SP 13506-900, Brazil

${ }^{2}$ Department of Internal Medicine, State University of Campinas, Campinas, Brazil

Full list of author information is available at the end of the article
}

C The Author(s). 2020 Open Access This article is licensed under a Creative Commons Attribution 4.0 International License, which permits use, sharing, adaptation, distribution and reproduction in any medium or format, as long as you give appropriate credit to the original author(s) and the source, provide a link to the Creative Commons licence, and indicate if changes were made. The images or other third party material in this article are included in the article's Creative Commons licence, unless indicated otherwise in a credit line to the material. If material is not included in the article's Creative Commons licence and your intended use is not permitted by statutory regulation or exceeds the permitted use, you will need to obtain permission directly from the copyright holder. To view a copy of this licence, visit http://creativecommons.org/licenses/by/4.0/. The Creative Commons Public Domain Dedication waiver (http://creativecommons.org/publicdomain/zero/1.0/) applies to the data made available in this article, unless otherwise stated in a credit line to the data. 
(Continued from previous page)

Conclusions: These data demonstrate that even a short period of detraining is harmful for elderly women who regularly participate in a program of strength training, since it impairs physical performance, insulin sensitivity and cholesterol metabolism.

Keywords: Aging, Inflammation, Physical exercise

\section{Background}

Physical inactivity has been considered an independent risk factor for development of several diseases such as cardiovascular diseases, dyslipidemia, insulin resistance, type 2 diabetes, and some cancers [1-4]. Furthermore, aging has been strongly associated with chronic subclinical inflammation, which in turn increases the risk of several chronic diseases [5]. A negative correlation has been observed between strength and inflammatory markers in the elderly [6]. On the other hand, resistance exercise training can attenuate systemic inflammation as well as promoting muscle mass maintenance during aging $[5,7]$. The anti-inflammatory effects of exercise may have an important role since higher levels of proinflammatory markers are associated with muscle catabolism [8-10]. Indeed, resistance exercise training can reduce lean mass loss, and therefore promotes maintenance of autonomy in the elderly [11-13].

Elevated levels of pro-inflammatory markers are strongly associated with increased risk of developing diabetes, cardiovascular diseases, and some cancers [5, 14]. Moreover, obesity and visceral adiposity show positive correlation with elevated levels of pro-inflammatory cytokines $[15,16]$, and adipose tissue inflammation seems to contribute with muscle wasting [17]. Likewise, studies have associated some chronic diseases to elevated proinflammatory cytokine levels as a consequence of the aging process $[5,18,19]$. In addition, circulating levels of IL- 6 and TNF- $\alpha$ are higher in the elderly than in young or middle-aged individuals $[15,20]$. Such an increase of circulating pro-inflammatory cytokines observed during aging may result from a combination of imbalanced immune function, presence of disease condition, reduced levels of physical activity, and increased fat mass $[5,21-$ 23]. Conversely, several groups have found a negative correlation between physical activity levels and proinflammatory markers, i.e., higher levels of physical activity are associated with lower levels of circulating inflammatory markers in the elderly [24-29]. In addition, strength trained elderly women presented reduced levels of TNF- $\alpha$, when compared to non-exercised elderly women [30]. Furthermore, a review of researches analyzing the effects of exercise on inflammation in the elderly suggested that increasing physical activity levels may be an important tool to lower inflammation in aging [31]. Thus, it seems clear that long-term exercise training can be a useful therapy to reduce inflammation during the aging process.

In parallel, elderly people are more likely to interrupt their physical activity than younger individuals due to disease, injuries, and incidence of depression [32]. Studies have shown that training interruption resulted in significant loss of upper and lower limb muscle strength in postmenopausal women [33] and reduced levels of aerobic and strength performance [34]. In addition to these changes related to strength performance, detraining may also affect metabolic biomarkers and endothelial health [35]. Since increased metabolic disturbances are highly prevalent in older people, mainly in those with obesity, it becomes important to understand the impacts of detraining in the elderly.

Despite the evidence showing the benefits of exercise training for the elderly, there is limited research regarding the detrimental effects that detraining may exert in the inflammatory and metabolic profile of this group. Thus, the current study aimed to investigate whether a 4-week detraining period was able to blunt the benefits of 4 months strength training in elderly women.

\section{Methods}

The study was approved by the Institutional Ethics Review Board at the Sao Paulo State University (UNESP) and was carried out in accordance with the Declaration of Helsinki from 1964 and revised in 2000. All participants included in the study signed a written informed consent and provided a medical authorization for physical exercise practice.

\section{Participants}

Seventeen physically active elderly women participated in the study. Participants were included in the study if they met the following inclusion criteria: a minimum of 60 years old and regular participation of 3 times a week in the resistance training provided by the State University of São Paulo (UNESP - Rio Claro). All volunteers accomplished at least $75 \%$ of the exercise sessions for 4 months (March to June). The training session was structured with stretching exercises in warm up, and resistance training as the major part. Each session lasted $1 \mathrm{~h}$, with resistance training of $40 \mathrm{~min}$. All participants performed the same exercises on a rotating system, being repeated on the 3 days of the week (Monday, Wednesday 
and Friday). The resistance training consists of three sets of 15 repetition maximum in the following exercises: lat pulldowns (latissimus dorsi), triceps pushdown (triceps), pec deck fly (chest), leg press (quadriceps), dumbbell curls (biceps), lateral raises (shoulders), standing calf raises (gastrocnemius). With respect to training load, participants were encouraged to choose a load that allowed them to perform up to 15 repetitions. Thus, when the participants were able to perform more than 15 repetitions, the load was adjusted and under supervision of a physical educator. Participants with any mental, neurological, muscular, and/or osteo-articular contraindications that limited or made impossible the accomplishment of the protocol of exercises during the classes and evaluation, or who missed 1 evaluation, or who had more than 2 absences in the month were excluded from the study. No participants were diabetic, nor had other metabolic diseases, or were in use of medications that interfered with insulin activity or glucose and fatty acid metabolism.

\section{Detraining}

On the day after the last exercise session, blood samples and physical assessment for base line data were collected. Blood was sampled from elderly women in the morning (7:00 to 8:00 am) after a 10-h overnight fasting. The physical assessment was carried out in the afternoon. Following this, all participants were oriented to not perform any physical exercise during the next 4 weeks. After this period the participants returned to the Lab for collection of blood samples and physical parameters evaluation in the same conditions applied for baseline to assess the detraining effects in these variables (Figure S1). We can assure that all volunteers neither attended other physical activity programs nor performed physical exercise during this detraining period since we questioned them on this matter. Thus, the detraining of the current study consists of 4 weeks without performing any physical exercise.

\section{Anthropometric variables}

Body mass was obtained using a mechanical scale with an accuracy of $0.1 \mathrm{~kg}$ (Welmy, SP, Brazil), and height was determined with a stadiometer (Sanny, SP, Brazil), fixed to the wall, with an accuracy of $0.01 \mathrm{~m}$ as previously described [36].

\section{Metabolic variables}

Total cholesterol and its fractions, triglycerides, glycemia, and insulin blood levels were assessed before and after the detraining protocol. Blood was sampled from elderly women in the morning after an overnight fasting in 2 moments, approximately $24 \mathrm{~h}$ after the last training session and 1 day before starting over again, i.e., following 4 weeks of detraining. As the training session had mild to moderate intensity, we decided to collect the samples 1 day after the last training session to avoid significant alterations disturbances in metabolic and inflammatory parameters, as previously performed [37, 38]. The blood was collected in tubes containing EDTA and centrifuged at $1100 \mathrm{~g}$ for $20 \mathrm{~min}$ at $4{ }^{\circ} \mathrm{C}$. Serum samples were stored at $-20^{\circ} \mathrm{C}$ until analyzed. Insulin and adiponectin levels were assessed using a commercial ELISA kit according to the manufacturer's protocol, while triglycerides, total cholesterol and its fraction were assessed by the colorimetric method. Glycemia was evaluated using a glucometer (Optium Xceeed - Abbot, Berkshire, England).

\section{HOMA-IR}

HOMA-IR was used as a proxy measure of whole body insulin sensitivity using the following formula (fasting serum insulin $(\mu \mathrm{U} / \mathrm{ml}) \times$ fasting plasma glucose $(\mathrm{mmol}$ $\left.\left.1^{-1}\right) / 22.5\right)[39]$.

\section{Multiplex bead Array platform}

Blood samples were collected and centrifuged, and the blood serum samples were stored at $-20^{\circ} \mathrm{C}$ until use. IL-1 $\beta$, IL-4, IL-6, IL-10, IL-13, TNF- $\alpha$, IFN $\gamma$, and MCP-1 were quantified with a Milliplex Map Human Cyotkine/ Chemokine Magnetic Bead Panel (Merck Millipore, Germany) according to the manufacturer's instructions and read on a Luminex Magpix instrument (Luminex, Austin, TX, USA). Data were analyzed with xPONENT 4.2 software (Luminex) as previously described [40].

\section{Physical activity variables \\ Physical activity level}

Physical activity levels were self-reported through the score obtained with the Baecke questionnaire modified for the elderly. The Baecke questionnaire consists of 10 questions related to basic activity, leisure time utilization, and physical activity, as previously described [41].

\section{Strength performance}

To evaluate the upper limb strength, the test of the American Alliance for Health, Physical Education, Recreation and Dance (AAHPERD) was used. In this test, the participant sits in an armless chair and performs the maximal number of elbow flexion for $30 \mathrm{~s}$. The participants performed the test twice and the higher value of repetition between the two tries is considered to measure the resistance strength $[42,43]$. The $30 \mathrm{~s}$ chair test was used to assess lower limb performance. The volunteer must sit on a chair with a straight back without arm rests and stand as many times as possible in $30 \mathrm{~s}[44,45]$. 


\section{Flexibility}

The Wells bench test was used as a way to measure muscular flexibility in lower limbs. This test consists of a small wooden apparatus with a metric scale on its surface. The individual sits on the floor with both legs fully extended and with the sole of the foot in one of the grooves, and then extends their hands far as possible in order to measure the score [46].

\section{Statistical analyses}

Participants' characterizing data (age, mass, height, and anthropometric data) were described as mean and standard deviation. To verify data distribution the ShapiroWilk test was used. In addition, outlier cases were calculated from the Grubbs test and then extreme values were excluded from analyzes. In normal distribution situation, the inflammatory profile, functional capacity components, and metabolic analysis of the participants were compared by the $\mathrm{T}$ Test (Student's T-Test) at two moments, pre detraining and post detraining. For non-normal distribution, the Friedman test was used when comparing the pre and post detraining in the aforementioned variables. In the case of a significant difference indicated by the Friedman test, the Wilcoxon test was adopted as equivalent to post hoc. The Cohen's d was used to verify the magnitude of detraining. A significance level of $5 \%$ was accepted for all analyzes.

\section{Results}

\section{Effects of detraining on physical activity variables}

Table 1 shows age, average program participation, height, mass and body mass index (BMI). No significant change between the baseline (Pre) and Post detraining period (Post) for both body mass and BMI were observed (Table 1). With regard to physical parameters, a significant reduction was observed in strength performance and flexibility after the detraining period as measured by the Wells bench test ( $26 \pm 7$ to $25 \pm 7 \mathrm{~cm}$; $p=0.015$, and small effect with $d=0.19), 30 \mathrm{~s}$ chair (18 \pm 4 to $16 \pm 3$ number of stands; $p=0.009$, and small effect $d=0.46)$ and upper limb test ( $34 \pm 5$ to $32 \pm 4$ repetitions; $p=0.006$, and medium effect $d=0.57$ ) (Fig. 1ac, and Supplemental Table 1).

\section{Metabolic parameters after the $\mathbf{4}$ week detraining period} No significant difference was found following the detraining period for both blood glucose $(p=0.26)$, and insulin $(p=0.37)$ (Fig. 2a and $\mathrm{b}$, and Supplemental Table 1). However, when HOMA-IR, a proxy measure of whole body insulin sensitivity, before and after the detraining period was compared, a significant increase in this index was observed $(0.72 \pm 0.14$ to $0.81 \pm 0.23 ; p=$ 0.029 , and small effect with $d=0.47$ ) (Fig. 2c, and Supplemental Table 1). We then evaluated the effects of the 4 week detraining period over the lipid profile. With respect to triglyceride levels, no significant change was observed when comparing Pre-detraining and Postdetraining $(p=0.46)$ (Fig. 3a, and Supplemental Table 1). On the other hand, the detraining period resulted in a significant increase in total blood cholesterol (178.21 \pm 23.64 to $220.90 \pm 64.98 \mathrm{mg} / \mathrm{dL} ; p=0.008$, and large effect with $d=0.87)$ and in LDL fraction $(111.79 \pm 21.09$ to $155.33 \pm 60.95 \mathrm{mg} / \mathrm{dL} ; p=0.048$, and large effect with $d=0.95$ ) (Fig. 3b and c, and Supplemental Table 1). However, no significant alteration in HDL $(p=0.95)$ and VLDL $(p=0.46)$ cholesterol fractions were found when comparing the two moments (Fig. 3d and e, and Supplemental Table 1).

Table 1 Physical characteristics and age, mean and standard deviation ( $n=17)$

\begin{tabular}{lcc}
\hline Characteristics & Pre values & Post values \\
\hline Age (years) & $68 \pm 4.4$ & $68 \pm 4.5$ \\
Mass $(\mathrm{kg})$ & $66 \pm 12.6$ & $66.7 \pm 12.7$ \\
Height $(\mathrm{m})$ & $1.61 \pm 0.06$ & $1.61 \pm 0.06$ \\
& & \\
BMI $\left(\mathrm{kg} / \mathrm{m}^{2}\right)$ & $25.6 \pm 4.7$ & $25.7 \pm 4.8$ \\
\hline
\end{tabular}



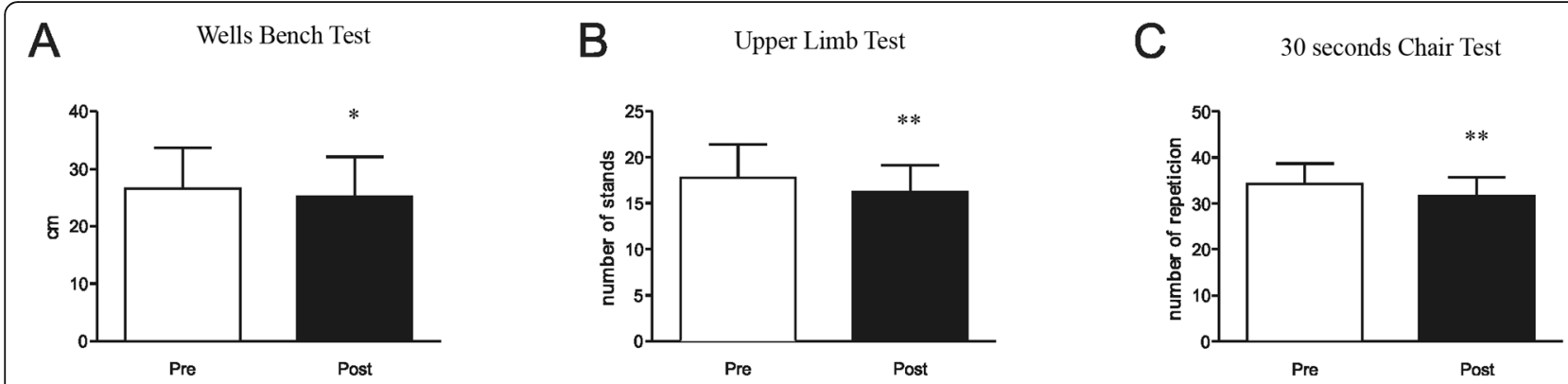

Fig. 1 Effects of a detraining period on physical activity levels. a Wells bench test, $\mathbf{b} 30 \mathrm{~s}$ chair stand test, and $\mathbf{c}$ upper limb resistance test in two moments before (Pre) and after (Post) a 4 week detraining period. Data are presented as means \pm standard deviation, ${ }^{*} P<0.05$ vs Pre, and ${ }^{* *} P<$ 0.01 vs Pre

\section{Effects of detraining on the inflammatory status}

We subsequently decided to investigate whether this detraining period was able to change the inflammatory profile of elderly women who regularly participate in a program of strength training. For this purpose, a wide investigation in circulating cytokine levels by using a multiplex assay was performed. Regarding inflammatory cytokines, no significant changes were observed for IL$1 \beta(p=0.31)$, IL-6 $(p=0.22)$, TNF- $\alpha(p=0.34)$, IFN $\gamma$ $(p=0.34)$, and MCP-1 $(p=0.36)$ after the detraining period (Fig. 4a-e, and Supplemental Table 1). In the same manner, no significant alterations in anti-inflammatory cytokines such as IL-4 $(p=0.97)$ and IL-10 $(p=0.27)$ were observed (Fig. 5a and b, and Supplemental Table 1). However, when another important Th2 cytokine such as IL-13 was assessed, a significant reduction was observed after the detraining period $(44.84 \pm 100.85$ to $35.84 \pm 78.89 \mathrm{pg} /$ $\mathrm{mL} ; p=0.03$, and small effect with $d<0.2$ ) (Fig. $5 \mathrm{c}$, and Supplemental Table 1).

\section{Effects of a short detraining period in lipopolysaccharide} circulating levels in physically active aging women

Since physical inactivity has been associated with increased pro-inflammatory cytokines, we hypothesized that a detraining period may induce an increase in the blood levels of lipopolysaccharide (LPS), which in turn would increase activation of inflammatory pathways in insulin target tissues. However, our data demonstrated that a 4 week period of detraining is not enough to increase circulating LPS levels $(p=0.25)$ (Fig. 6a, and Supplemental Table 1).

\section{Discussion}

In the current study, we demonstrated that a relatively short detraining period of only 4 weeks, was able to impair insulin sensitivity and cholesterol metabolism. Herein, we also observed that this detraining period significantly reduced IL-13, a Th2 cytokine that induces M2 macrophage polarization. However, this detraining period was not able to increase blood levels of proinflammatory cytokines and did not result in significant body mass gain or changes in BMI of elderly women who regularly participate in a program of strength training.

In accordance, middle-aged women subjected to Pilates training did not show difference in body mass between the Pre and Post 4 week detraining periods [47]. On the other hand, the research of Gastebois and contributors observed that the same detraining period induces a significant change in body composition as evidenced by reduced lean mass and increased fat mass, despite any change in body weight [48]. Since body composition was not assessed in the current study, we cannot rule out that our elderly women did not present such alterations. In

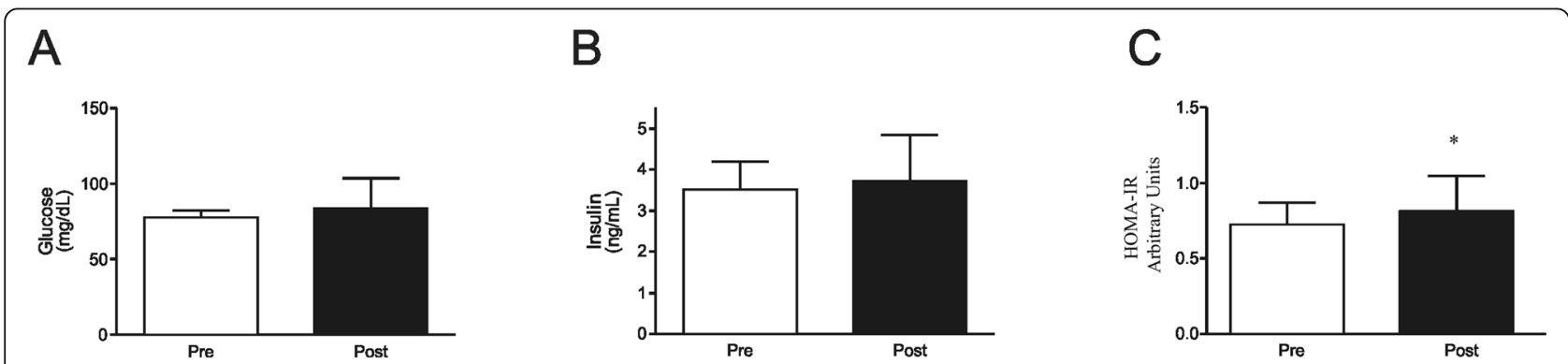

Fig. 2 Detraining effects on glucose metabolism. a fasting blood glucose, b fasting serum insulin, and c HOMA-IR in two moments before (Pre) and after (Post) a 4 week detraining period. Data are presented as means \pm standard deviation, ${ }^{*} P<0.05$ vs Pre 


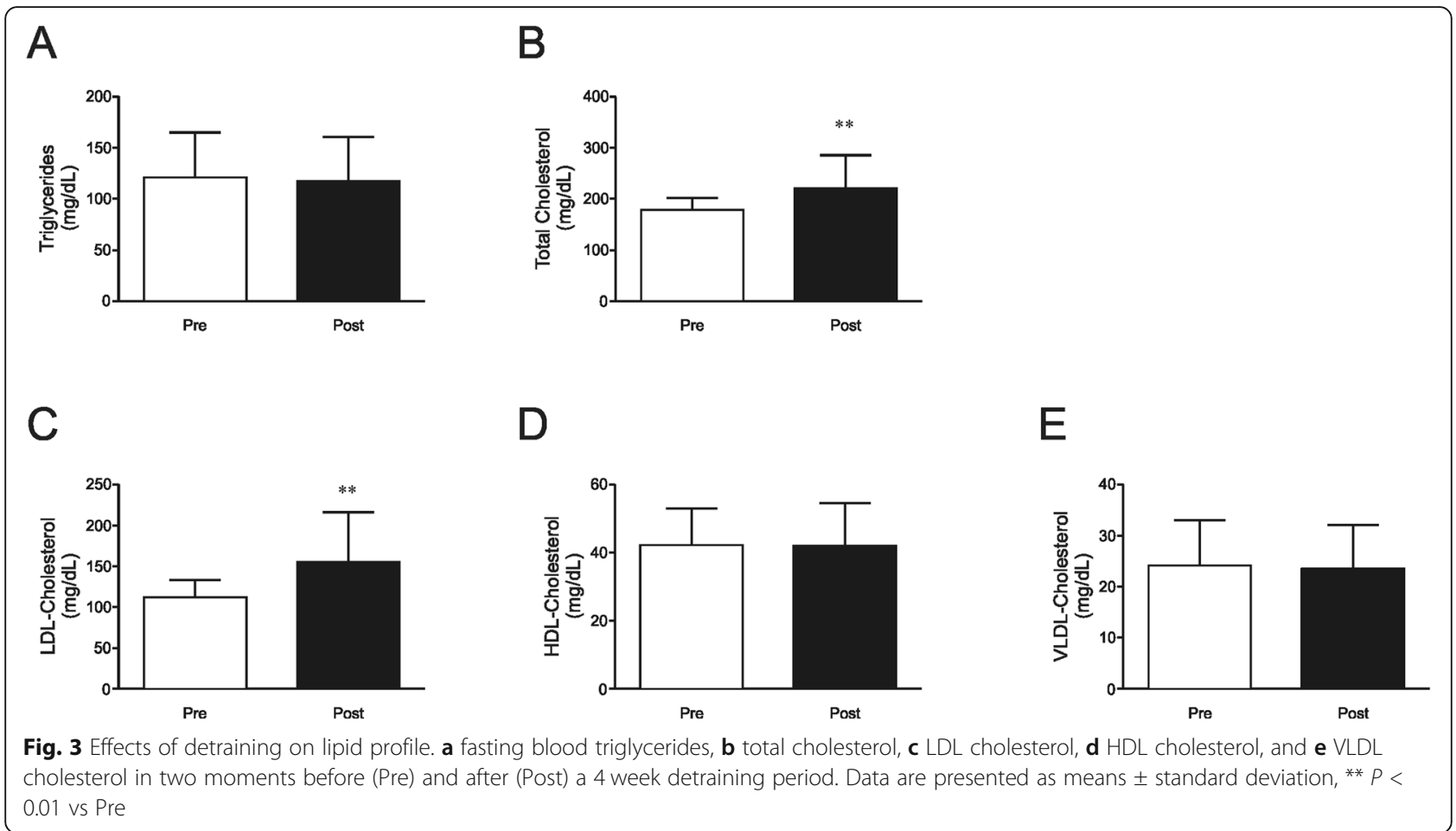

addition, although we strongly recommended that their diets should be unaltered during the 4-week detraining period, it is tempting to speculate that they may have reduced caloric intake, which in turn would contribute to the absence of weight gain in the current study. Thus, it seems evident that assessing body composition and food intake certainly would be of major importance to evaluate the detraining effects on anthropometric parameters in future studies.

Since in the present study elderly women who regularly participate in a program of strength training were evaluated, it would be expected that the 4 week

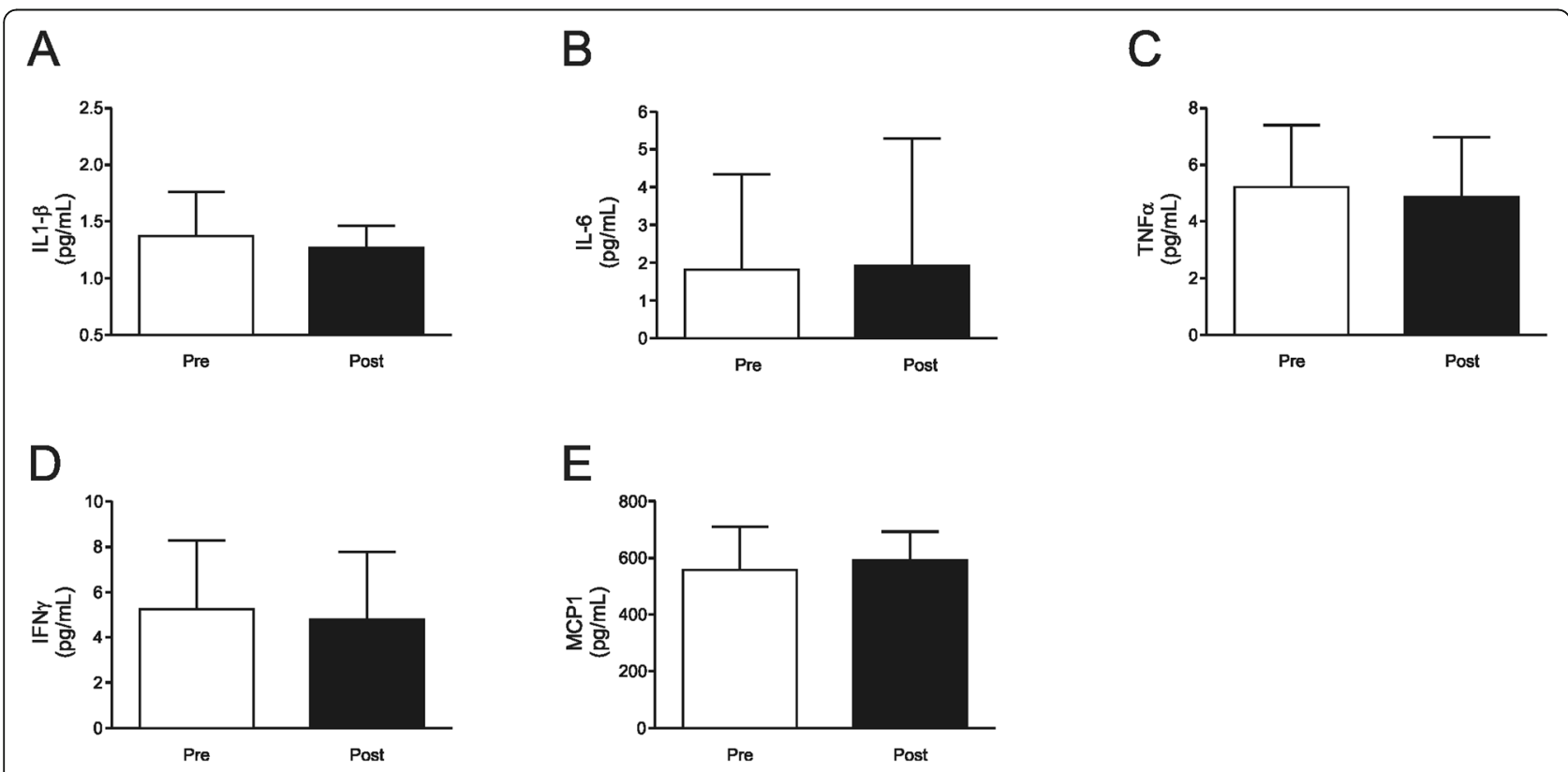

Fig. 4 Pro-inflammatory profile after detraining. a IL-1 $\beta, \mathbf{b} \| \mathrm{L}-6, \mathbf{c}$ TNF- $a, \mathbf{d}$ IFN- $\gamma$, and e MCP-1 in two moments before (Pre) and after (Post) a 4 week detraining period. Data are presented as means \pm standard deviation 


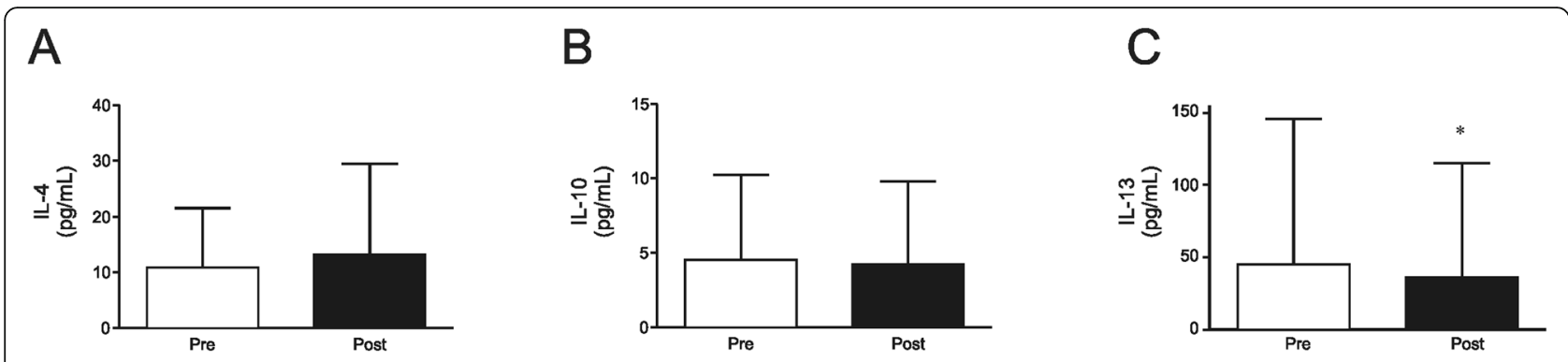

Fig. 5 Effects of detraining on anti-inflammatory cytokines. a IL-4, b IL-10, and $\mathbf{c} \| \mathrm{L}-13$ in two moments before (Pre) and after (Post) a 4 week detraining period. Data are presented as means \pm standard deviation, ${ }^{*} P<0.05$ vs Pre

detraining resulted in a significant decrease in physical performance. In this regard, our participants showed reduced performance in flexibility (Wells bench test) as well as in strength performance of lower limbs (30 s chair sit to stand) and upper limbs (upper limb test) when comparing the Post detraining period with baseline. In accordance, a recent study showed that a 12 week detraining period decreases the performance in the Wells bench test, $30 \mathrm{~s}$ chair sit to stand and in upper muscle strength performance [49]. Together these findings confirm that detraining, even for a short period such as 4 weeks, induces significant loss in flexibility and strength performance.

The present study demonstrates that a 4-week detraining period may deteriorate the health of elderly women who regularly participate in a program of strength training, as we observed a significant increase in total cholesterol levels, driven by the elevation of its LDL fraction. Also, resistance training is particularly positive for elderly women since this kind of exercise improves strength and prevents muscle mass loss, which, in turn, would be useful to prevent health deterioration [7]. Taking all these into account, it becomes evident that elderly women who regularly participate in a program of

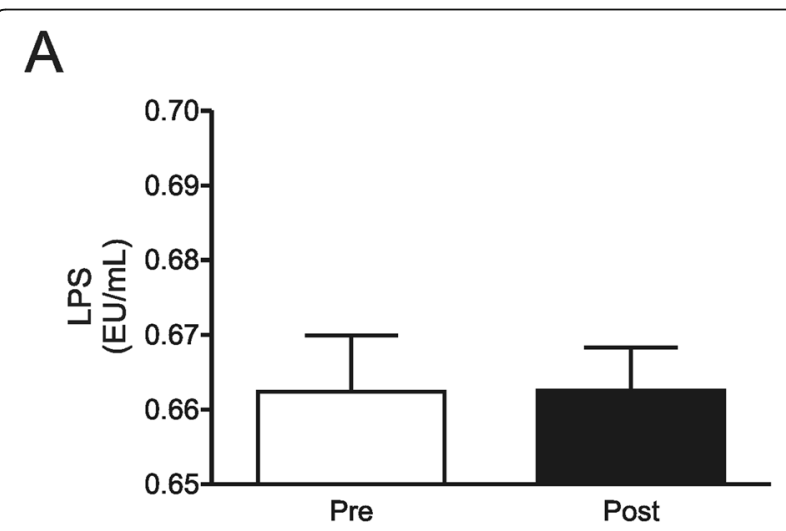

Fig. 6 LPS levels after a 4 week detraining period. a LPS blood levels in two moments before (Pre) and after (Post) a 4 week detraining period. Data are presented as means \pm standard deviation strength training should avoid stopping their physical activity regimen for periods longer than 2 to 3 weeks.

Our results showed that the 4-week detraining period did not induced an increase in both glucose and insulin blood levels. Corroborating these results, two studies of independent groups that used the same protocol as ours, i.e. a 4-week detraining period, did not observe any significant difference in both fasting glycemia and insulinemia after detraining $[48,50]$. However, when these two parameters are analyzed together, i.e. by using the HOMA-IR index, a proxy measure of whole body insulin sensitivity, we verified a significant reduction in insulin sensitivity of elderly women subjected to a 4 week detraining period. Fatouros and coworkers observed that a 24-week detraining period increased glycaemia and HOMA-IR in trained elderly [51]. Taking the aforementioned into account, we can hypothesize that the detraining influence on metabolic parameters seems to be closely related to its length, i.e., the longer the duration of detraining, the greater the impact on metabolic parameters. Thus, there is still a need for further studies to evaluate the impact of detraining duration on metabolic changes.

The 4-week detraining period did not induce any significant change in pro-inflammatory markers such as TNF- $\alpha$, IL-1 $\beta$, IL-6, and MCP- 1 . These results are consistent with previous studies which also found no increase in TNF- $\alpha$ after a detraining period of 4 weeks $[52,53]$. On the other hand, 8 weeks of detraining was able to increase the ratio neutrophil/lymphocyte, an index of systemic inflammation, which also showed a positive correlation with insulin resistance [54]. Taken together these data indicate that the increase of inflammation during a detraining period may occur slowly or even have a late onset, since systemic significant changes can be observed only after 8 weeks. In addition, our results do not allow ruling out the occurrence of changes in the production of pro-inflammatory cytokines at tissue level. Further invasive studies are needed to elucidate the spatial and temporal kinetics of increased inflammation in the course of the detraining process. 
Despite not observing an increase in the proinflammatory markers, it was observed that the 4-week detraining period resulted in a significant reduction in the circulating levels of IL-13. Such change may have major relevance since this cytokine strongly induces M2 macrophage polarization, that is important to the maintenance of physiological insulin sensitivity $[55,56]$. Furthermore, studies have shown that improvements in insulin sensitivity occur due to action of IL-4 and IL-13 in the JAK1/STAT6 pathway and that IL-13 promotes suppression of hepatic glucose production [57, 58]. In this regard it is tempting to speculate that a circulating IL13 decrease may be interfering with anti-inflammatory responses, and therefore have a role in increasing insulin resistance in the elderly women subjected to a detraining period as observed in the current study. Thus, further studies are necessary to elucidate this point.

The current study presents some limitations. The main limitation is certainly the absence of a control group, i.e., a group of elderly women who continue exercising. The best conduct would be to assess pre and post exercise parameters in both experimental and control groups. However, we did find significant decreases in some physical parameters (flexibility and strength performance) when comparing pre to post exercise, therefore, we believe that the alterations found in this study are most likely a result of the detraining period. Thus, our results may be considered meaningful inspite of the lack of a control group. Another limitation is the absence of rigorous monitoring of physical activity behavior during the detraining period, to avoid possible interferences of any increase of daily physical activity during the detraining in pro-inflammatory cytokines, or in physical and metabolic parameters. However, we found significant changes in some measurements after the detraining period, which in turn indicated that our group of elderly women avoided performing physical activity during the detraining. The other important limitation is certainly the lack of any nutritional assessment of the participants before, during, or after the detraining period in order to exclude the possible interferences of usual dietary intake, or even the last meal in parameters such as body mass, circulating cytokine levels, LPS levels, and also in HOMA-IR. In addition, the sample size is certainly a limitation that have weakened the statistical power, thus interfering in the size effect and detection of significant differences. Further studies should take into account these factors.

Thus, despite these above limitations, the current study has contributed to its field, since we observed that even a short period of detraining was able to induce metabolic disturbances, which in turn highlighted the importance of avoiding training interruption for elderly women who regularly participate in a program of strength training.

\section{Conclusion}

In summary, we demonstrate that a 4-week detraining period impairs insulin sensitivity and cholesterol metabolism, as evidenced by increased HOMA-IR, and cholesterol LDL fraction, along with a reduction in circulating levels of IL-13, a Th2 response inductor. However, this short period was not able to induce alterations in pro-inflammatory cytokine circulating levels in elderly women who regularly participate in a program of strength training.

\section{Supplementary information}

Supplementary information accompanies this paper at https://doi.org/10. 1186/s11556-020-00244-8.

Additional file 1.

\section{Acknowledgements}

We also acknowledge the financial support CEPID201307607-8, OCRC (Centro de Pesquisa em Obesidade e Comorbidades), and INCT (Instituto Nacional de Ciência e Tecnologia de Obesidade e Diabetes) CNPq (573856/2008-7) and FAPESP (2012/15009-0). The authors thank C. Y. Sibuya (Department of Physical Education, UNESP, Rio Claro, Sao Paulo) and E. Custódio (Department of Physical Education, UNESP, Rio Claro, Sao Paulo) for their technical assistance.

\section{Authors' contributions}

C.P.C.: researched data, contributed to discussion, wrote/reviewed/edited manuscript; A.M.S.: researched data, wrote/reviewed/edited manuscript; R.M.T: wrote/reviewed/edited manuscript; D.G.: researched data and reviewed/edited manuscript; G.Z.R.: wrote/reviewed/edited manuscript; M.J.A.S.: Contributed to discussion and reviewed/edited manuscript; A.G.O.: contributed to discussion, wrote/reviewed/edited manuscript. All authors read and approved the final manuscript

\section{Funding}

1- INCT (Instituto Nacional de Ciência e Tecnologia de Obesidade e

Diabetes):- CNPq 573856/2008-7.

- FAPESP 2012/15009-0.

2 -CEPID OCRC (Centro de Pesquisa em Obesidade e Comorbidades) FAPESP. 2013/07607-8

\section{Availability of data and materials} Not applicable.

\section{Ethics approval and consent to participate}

The study was approved by the Institutional Ethics Review Board at the Sao Paulo State University-UNESP (number 44689015.9.0000.5465) and was carried out in accordance with the Declaration of Helsinki from 1964 and revised in 2000. All subjects included in the study signed a written informed consent and completed a comprehensive medical evaluation.

\section{Consent for publication}

The consent for publication was signed in the same form used to consent to participate.

\section{Competing interests}

All authors declare no conflict of interests.

\section{Author details}

${ }^{1}$ Department of Physical Education, Bioscience Institute, Sao Paulo State University (UNESP), Rio Claro, SP 13506-900, Brazil. ²Department of Internal Medicine, State University of Campinas, Campinas, Brazil. ${ }^{3}$ The Human Performance Research Group, Technological Federal University of Paraná, Curitiba, Brazil. 
Received: 10 January 2020 Accepted: 14 August 2020 Published online: 26 August 2020

\section{References}

1. Santacruz A, et al. Interplay between weight loss and gut microbiota composition in overweight adolescents. Obesity. 2009;17(10):1906-15.

2. Shaw K, et al. Exercise for overweight or obesity. Cochrane Database Syst Rev. 2006;4:CD003817.

3. Bellou V, et al. Risk factors for type 2 diabetes mellitus: an exposure-wide umbrella review of meta-analyses. PLoS One. 2018;13(3):e0194127.

4. Wahid A, et al. Quantifying the Association Between Physical Activity and Cardiovascular Disease and Diabetes: A Systematic Review and MetaAnalysis. J Am Heart Assoc. 2016;5(9):e002495.

5. Flynn MG, Markofski MM, Carrillo AE. Elevated inflammatory status and increased risk of chronic disease in chronological aging: Inflamm-aging or Inflamm-inactivity? Aging Dis. 2019;10(1):147-56.

6. Visser $M$, et al. Relationship of interleukin-6 and tumor necrosis factor-alpha with muscle mass and muscle strength in elderly men and women: the health ABC study. J Gerontol A Biol Sci Med Sci. 2002;57(5):M326-32.

7. Johnston AP, De Lisio M, Parise G. Resistance training, sarcopenia, and the mitochondrial theory of aging. Appl Physiol Nutr Metab. 2008;33(1):191-9.

8. Budui SL, Rossi AP, Zamboni M. The pathogenetic bases of sarcopenia. Clin Cases Miner Bone Metab. 2015;12(1):22-6.

9. Rolland $Y$, et al. Sarcopenia: its assessment, etiology, pathogenesis, consequences and future perspectives. J Nutr Health Aging. 2008;12(7):433-50.

10. Yoo SZ, et al. Role of exercise in age-related sarcopenia. J Exerc Rehabil. 2018;14(4):551-8.

11. Lutz CT, Quinn LS. Sarcopenia, obesity, and natural killer cell immune senescence in aging: altered cytokine levels as a common mechanism. Aging (Albany NY). 2012;4(8):535-46.

12. Fragala MS, et al. Muscle quality index improves with resistance exercise training in older adults. Exp Gerontol. 2014;53:1-6.

13. Zampieri $\mathrm{S}$, et al. Lifelong physical exercise delays age-associated skeletal muscle decline. J Gerontol A Biol Sci Med Sci. 2015;70(2):163-73.

14. Collaboration, C.R.P.C.H.D.G, et al. Association between $\mathrm{C}$ reactive protein and coronary heart disease: mendelian randomisation analysis based on individual participant data. BMJ. 2011;342:d548.

15. Graßmann S, et al. Association between peripheral Adipokines and inflammation markers: a systematic review and meta-analysis. Obesity. 2017; 25(10):1776-85.

16. Volp ACP, et al. Capacidade dos biomarcadores inflamatórios em predizer a síndrome metabólica: inflammation biomarkers capacity in predicting the metabolic syndrome. Arq Bras Endocrinol Metabol. 2008;52:537-49.

17. Pellegrinelli $V$, et al. Human adipocytes induce inflammation and atrophy in muscle cells during obesity. Diabetes. 2015;64(9):3121-34.

18. Franceschi C. Inflammaging as a major characteristic of old people: can it be prevented or cured? Nutr Rev. 2007;65(s3):S173-6.

19. Franceschi $\mathrm{C}$, et al. Inflammaging and anti-inflammaging: a systemic perspective on aging and longevity emerged from studies in humans. Mech Ageing Dev. 2007;128(1):92-105.

20. Ferrucci $L$, et al. The origins of age-related proinflammatory state. Blood. 2005;105(6):2294-9.

21. Addison $\mathrm{O}$, et al. Inflammation, aging, and adiposity: implications for physical therapists. J Geriatr Phys Ther. 2012;35(2):86-94.

22. Beharka AA, et al. Interleukin-6 production does not increase with age. J Gerontol A Biol Sci Med Sci. 2001;56(2):B81-8.

23. Krabbe KS, et al. Ageing is associated with a prolonged fever response in human endotoxemia. Clin Diagn Lab Immunol. 2001;8(2):333-8.

24. Albert MA, Glynn RJ, Ridker PM. Effect of physical activity on serum Creactive protein. Am J Cardiol. 2004;93(2):221-5.

25. Colbert LH, et al. Physical activity, exercise, and inflammatory markers in older adults: findings from the health, aging and body composition study. J Am Geriatr Soc. 2004;52(7):1098-104.

26. Mikkelsen UR, et al. Life-long endurance exercise in humans: circulating levels of inflammatory markers and leg muscle size. Mech Ageing Dev. 2013:134(11-12):531-40.

27. Rahimi K, et al. Correlation of exercise capacity with high-sensitive Creactive protein in patients with stable coronary artery disease. Am Heart J. 2005;150(6):1282-9.

28. Valentine RJ, et al. Stronger relationship between central adiposity and Creactive protein in older women than men. Menopause. 2009;16(1):84-9.
29. $Y u Z$ Z, et al. Associations of physical activity with inflammatory factors, adipocytokines, and metabolic syndrome in middle-aged and older chinese people. Circulation. 2009;119(23):2969-77.

30. Greiwe JS, et al. Resistance exercise decreases skeletal muscle tumor necrosis factor alpha in frail elderly humans. FASEB J. 2001;15(2):475-82.

31. Nicklas BJ, Brinkley TE. Exercise training as a treatment for chronic inflammation in the elderly. Exerc Sport Sci Rev. 2009;37(4):165-70.

32. Rubenstein LZ. Falls in older people: epidemiology, risk factors and strategies for prevention. Age Ageing. 2006;35(Suppl 2):ii37-41.

33. Elliott KJ, Sale C, Cable NT. Effects of resistance training and detraining on muscle strength and blood lipid profiles in postmenopausal women. $\mathrm{Br} \mathrm{J}$ Sports Med. 2002;36(5):340-4.

34. Ratel $\mathrm{S}$, et al. Detraining-induced alterations in metabolic and fitness markers after a multicomponent exercise-training program in older men. Appl Physiol Nutr Metab. 2012;37(1):72-9.

35. Soni AC, et al. Ghrelin, leptin, adiponectin, and insulin levels and concurrent and future weight change in overweight, postmenopausal women. Menopause. 2011;18(3):296-301.

36. Gordon CC, C.W, Roche AF. In: Lohman TG, Roche AF, Martorell R, editors. Stature, Recumbent length and weight, in Anthropometric standardization reference manual, vol. 3-8. Champaign: Human kinetics books; 1988.

37. Reihmane D, et al. Increase in IL-6, TNF-a, and MMP-9, but not SICAM-1, concentrations depends on exercise duration. Eur J Appl Physiol. 2013; 113(4):851-8

38. Macêdo Santiago $L$, et al. Effects of resistance training on Immunoinflammatory response, TNF-alpha gene expression, and body composition in elderly women. J Aging Res. 2018;2018:1467025.

39. Matthews DR, et al. Homeostasis model assessment: insulin resistance and beta-cell function from fasting plasma glucose and insulin concentrations in man. Diabetologia. 1985;28(7):412-9.

40. Elshal MF, McCoy JP. Multiplex bead array assays: performance evaluation and comparison of sensitivity to ELISA. Methods. 2006;38(4):317-23.

41. Voorrips LE, et al. A physical activity questionnaire for the elderly. Med Sci Sports Exerc. 1991:23(8):974-9.

42. Zago AS, Gobbi S. Normative values of functional fitness in 60-to-70 yearold women. Brazilian Journal of Science and Movement. 2003;11(2):77-86.

43. Osness WA, Clark M, Hoeger B, Raab W, Wiswell RD. Functional Fitness Assessment for Adults Over 60 Years (A field Based Assessment): Published Test Protocols. VA: American Alliance of health, Physical Education, Recreation and Dance; 1990. p. 24.

44. Rikli RE, Jones CJ. Development and validation of a functional fitness test for community-residing older adults. J Aging Phys Act. 1999;7(2):129-61.

45. Rikli RE, Jones CJ. Functional fitness normative scores for communityresiding older adults, ages 60-94. J Aging Phys Act. 1999;7(2):162-81.

46. Wells KF, Dillon EK. The sit and reach - a test of back and leg flexibility. Res Q Am Assoc Health Phys Educ Recreation. 1952;23(1):115-8.

47. Vaquero-Cristóbal $R$, et al. The effects of a reformer Pilates program on body composition and morphological characteristics in active women after a detraining period. Women Health. 2016;56(7):784-806.

48. Gastebois $C$, et al. Effects of training and detraining on adiponectin plasma concentration and muscle sensitivity in lean and overweight men. Eur J Appl Physiol. 2016;116(11-12):2135-44.

49. Orange ST, et al. The short-term training and detraining effects of supervised versus unsupervised resistance exercise in aging adults. J Strength Cond Res. 2018;33(10):2733-42.

50. Nikseresht M, Hafezi Ahmadi MR, Hedayati M. Detraining-induced alterations in adipokines and cardiometabolic risk factors after nonlinear periodized resistance and aerobic interval training in obese men. Appl Physiol Nutr Metab. 2016;41(10):1018-25.

51. Fatouros $I G$, et al. Leptin and adiponectin responses in overweight inactive elderly following resistance training and detraining are intensity related. J Clin Endocrinol Metab. 2005;90(11):5970-7.

52. Ahmadizad $\mathrm{S}$, et al. The effects of short-term high-intensity interval training vs. moderate-intensity continuous training on plasma levels of nesfatin-1 and inflammatory markers. Horm Mol Biol Clin Investig. 2015;21(3):165-73.

53. Nikseresht $\mathrm{M}$, et al. Inflammatory markers and adipocytokine responses to exercise training and detraining in men who are obese. J Strength Cond Res. 2014:28(12):3399-410.

54. Liao $\mathrm{YH}$, et al. Eight-week training cessation suppresses physiological stress but rapidly impairs health metabolic profiles and aerobic capacity in elite taekwondo athletes. PLoS One. 2016;11(7):e0160167. 
55. Paul WE, Zhu J. How are $T(H) 2$-type immune responses initiated and amplified? Nat Rev Immunol. 2010;10(4):225-35.

56. Hevener AL, et al. Macrophage PPAR gamma is required for normal skeletal muscle and hepatic insulin sensitivity and full antidiabetic effects of thiazolidinediones. J Clin Invest. 2007;117(6):1658-69.

57. Jiang H, Harris MB, Rothman P. IL-4/LL-13 signaling beyond JAK/STAT. J Allergy Clin Immunol. 2000;105(6 Pt 1):1063-70.

58. Stanya KJ, et al. Direct control of hepatic glucose production by interleukin13 in mice. J Clin Invest. 2013;123(1):261-71.

\section{Publisher's Note}

Springer Nature remains neutral with regard to jurisdictional claims in published maps and institutional affiliations.

Ready to submit your research? Choose BMC and benefit from:

- fast, convenient online submission

- thorough peer review by experienced researchers in your field

- rapid publication on acceptance

- support for research data, including large and complex data types

- gold Open Access which fosters wider collaboration and increased citations

- maximum visibility for your research: over $100 \mathrm{M}$ website views per year

At $\mathrm{BMC}$, research is always in progress.

Learn more biomedcentral.com/submissions 